\title{
3D models related to the publication: New record of Neosaimiri (Cebidae, Platyrrhini) from the late Middle Miocene of Peruvian Amazonia
}

\author{
Laurent Marivaux ${ }^{1 *}$, Rodolfo Salas-Gismondi ${ }^{2,3}$, Pierre-Olivier Antoine ${ }^{1}$ \\ ${ }^{1}$ Institut des Sciences de l'Évolution de Montpellier (ISEM, UMR 5554, CNRS/UM/IRD/EPHE), Université de Montpellier, place Eugène Bataillon, \\ 34095 Montpellier Cedex 05, France \\ ${ }^{2}$ Departamento de Paleontología de Vertebrados, Museo de Historia Natural - Universidad Nacional Mayor San Marcos (MUSM), Av. Arenales 1256 , \\ Lima 11, Peru \\ ${ }^{3}$ BioGeoCiencias Lab, Facultad de Ciencias y Filosofía/CIDIS, Universidad Peruana Cayetano Heredia, Avda. Honorio Delgado 430, Lima 31, Peru \\ *Corresponding author: Laurent.Marivaux@UMontpellier.fr
}

\begin{abstract}
This contribution contains the 3D models of the fossil teeth of a small-bodied platyrrhine primate, Neosaimiri cf. fieldsi (Cebinae, Cebidae, Platyrrhini) discovered from Laventan deposits (late Middle Miocene) of Peruvian Amazonia, San Martín Department (TAR-31: Tarapoto/Juan Guerra vertebrate fossil-bearing locus n³1). These fossils were described and figured in the following publication: Marivaux et al. (2020), New record of Neosaimiri (Cebidae, Platyrrhini) from the late Middle Miocene of Peruvian Amazonia. Journal of Human Evolution. https: //doi.org/10.1016/j.jhevol.2020.102835
\end{abstract}

Keywords: Laventan, Neogene, Paleobiogeography, Peru, Tropical South America

Submitted:2020-05-19, published online:2020-07-10. https://doi.org/10.18563/journal.m3.119

\section{INTRODUCTION}

We present here the 3D digital models of seven isolated teeth or fragments of teeth (Fig. 1; Table 1) documenting a fossil representative of Cebinae: Neosaimiri cf. fieldsi, a small-sized squirrel monkey-like primate (Cebidae, Platyrrhini). The fossils were recently discovered in Peruvian Amazonia (TAR-31, Tarapoto/Juan Guerra locus n ${ }^{\circ} 31$, San Martín Department, Peru) from fluvial deposits documenting the lower member of the Ipururo Formation (Sánchez Hernández et al., 1997; Hermoza et al., 2005). Biochronological evidence based on the TAR-31 mammal assemblage allows dating this new primate-bearing locality to the late Middle Miocene (ca. 13.1-12.6 Ma; i.e., Laventan South American Land Mammal Age [SALMA]; Marivaux et al., 2020). The dental specimens were recovered after wet-screening of about $550 \mathrm{~kg}$ of sediment at TAR-31 (August 2017 and 2018). Only three of the seven dental specimens attributed to this taxon are complete and well preserved. They consist of a third lower molar (m3; Fig. 1A), a deciduous second lower premolar (dp2; Fig. 1B), and a deciduous upper canine (DC1; Fig. 1C). The other fossil teeth are broken and the fragments document either halves or quarters of premolars (Fig. 1D-E) and molars (Fig. $1 \mathrm{~F}-\mathrm{G})$. Although limited, this new fossil material of Neosaimiri is critical because this taxon was so far only documented in the well-known La Venta locality, Colombia (Laventan SALMA, late Middle Miocene), with the species N. fieldsi Stirton, 1951. The La Venta fauna is famous for having yielded a wide array of crown platyrrhines. The occurrence of $N$. cf. fieldsi in coeval deposits of Peruvian Amazonia thus represents a second and southernmost record of that low-latitude genus in the
Inv nr.
MUSM-3888
MUSM-3890
MUSM-3895
MUSM-3891
Collection
right $\mathrm{m} 3$
left dp2
right DC1
lingual part of a fragmentary right $\mathrm{M} 1$ or
M2
MUSM-3892 distobuccal part of a fragmentary right upper molar (metacone region)
MUSM-3893 buccal part of a fragmentary right P3 or P4
MUSM-3894 lingual part of a fragmentary left P3 or P4

Table 1. List of models of Neosaimiri cf. fieldsi. Collection: Museo de Historia Natural - Universidad Nacional Mayor San Marcos, Lima, Peru.

Neotropics, thereby demonstrating its wide distribution along the northwestern edge of the Pebas Mega-Wetland System, in tropical western South America (Marivaux et al., 2020).

\section{METHODS}

Each specimen was scanned with a resolution of $6 \mu \mathrm{m}$ using a Xray $\mu \mathrm{CT}$ EasyTom 150 / Rx Solutions (Montpellier Ressources Imagerie, ISE-M, Montpellier, France). AVIZO 7.1 (Visualization Sciences Group) software was used for visualization, segmentation, and 3D rendering. The isolated teeth and fragment of teeth were prepared within a "labelfield" module of AVIZO, using the segmentation threshold selection tool. The 3D models are provided in .ply format, and thus can be opened with a wide range of freeware. The .ply files were generated with MorphoDig 1.5.3., an open-source 3D freeware (Lebrun, 
2018; https://morphomuseum.com/Pages/morphodig).

\section{ACKNOWLEDGEMENTS}

The 3D data presented in this work were produced through the technical facilities of the Montpellier RIO Imaging (MRI) platform (ISE-M, Université de Montpellier) and of the LabEx CeMEB. We particularly thank R. Lebrun and A.-L. Charruault (ISE-M, Université de Montpellier) for micro-CT scan acquisitions, treatments, and reconstructions. The paleontological fieldwork (August 2017-2018) and laboratory analyses were financially supported by The Leakey Foundation (L. Marivaux) and the National Geographic Society (P.-O. Antoine). This work also benefited from an "Investissements d'Avenir" grant managed by the Agence Nationale de la Recherche, France (CEBA, ANR-10-LABX-25-01). ISE-M publication $n^{\circ}$ 2020-131 Sud.

\section{BIBLIOGRAPHY}

Hermoza, W., Brusset, S., Baby, P., Gil, W., Roddaz, M., Guerrero, N., Bolaños, R., 2005. The Huallaga foreland basin evolution: thrust propagation in a deltaic environment, northern Peruvian Andes. Journal of South American Earth Sciences 19, 21-34. https://doi.org/10.1016/j.jsames.2004.06.005

Lebrun, R., 2018. MorphoDig, an open-source 3D freeware dedicated to biology. 5th International Paleontological Congress (IPC5) - The Fossil Week, July 9-13th, 2018 (Paris, France). Abstract volume, 399.

Marivaux, L., Aguirre-Díaz, W., Benites-Palomino, A., Billet, G., Boivin, M., Pujos, F., Salas-Gismondi, R., Tejada-Lara, J. V., Varas-Malca, R., Antoine, P.-O., 2020. New record of Neosaimiri (Cebidae, Platyrrhini) from the late Middle Miocene of Peruvian Amazonia. Journal of Human Evolution, https: //doi.org/10.1016/j.jhevol.2020.102835.

Sánchez Fernández, A. W., Chira Fernández, J. E., Valencia Muñoz, M. M., 1997. Geología de los cuadrángulos de Tarapoto, Papa Playa, Utcurarca y Yanayacu 13-k, 13-1, 14-k, 14-1. INGEMMET Boletín A 94, 237 pp. 


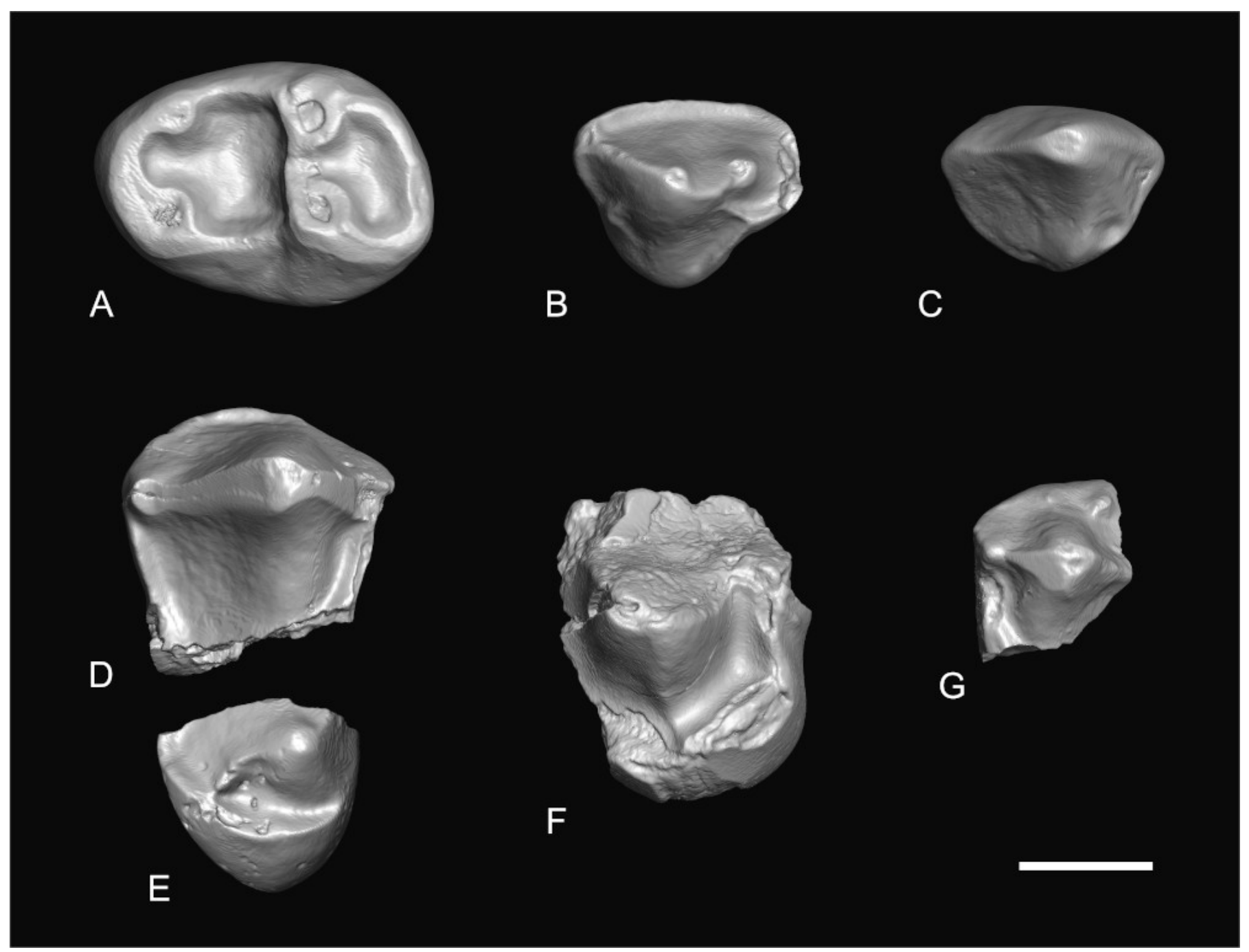

Figure 1. Fossil dental specimens of Neosaimiri cf. fieldsi from the late Middle Miocene (Laventan SALMA) of Tarapoto/Juan Guerra locus n³1 (TAR-31), San Martín Department, Peruvian Amazonia. A) MUSM-3888, right m3; B) MUSM-3890, left dp2; C) MUSM-3895, right DC1; D) MUSM-3893, buccal part of a fragmentary right P3 or P4; E) MUSM-3894, lingual part of a fragmentary left P3 or P4 (reversed); F) MUSM-3891, lingual part of a fragmentary right M1 or M2; G) MUSM-3892, distobuccal part of a fragmentary right upper molar (metacone region). Teeth from $A$ to $\mathrm{G}$ are in occlusal views. Scale bar $=1 \mathrm{~mm}$. 